This item was submitted to Loughborough's Research Repository by the author.

Items in Figshare are protected by copyright, with all rights reserved, unless otherwise indicated.

\title{
Athlete development, athlete rights and athlete welfare: a European Union perspective
}

PLEASE CITE THE PUBLISHED VERSION

http://dx.doi.org/10.1080/09523367.2013.765721

\section{PUBLISHER}

Routledge (@ Taylor \& Francis)

VERSION

AM (Accepted Manuscript)

\section{PUBLISHER STATEMENT}

This work is made available according to the conditions of the Creative Commons Attribution-NonCommercialNoDerivatives 4.0 International (CC BY-NC-ND 4.0) licence. Full details of this licence are available at: https://creativecommons.org/licenses/by-nc-nd/4.0/

\section{LICENCE}

CC BY-NC-ND 4.0

\section{REPOSITORY RECORD}

Henry, lan P.D.. 2019. "Athlete Development, Athlete Rights and Athlete Welfare: A European Union Perspective”. figshare. https://hdl.handle.net/2134/19325. 


\title{
Athlete Development, Athlete Rights \& Athlete Welfare: a European Union Perspective
}

\author{
Ian Henry, Centre for Olympic Studies and Research, School of Sport, Exercise and Health \\ Sciences, Loughborough University
}

\section{Abstract}

The issue of athlete 'dual careers' in elite sport and education or work has received increasing attention over recent years from a whole range of stakeholders. In particular the European Commission has engaged in research and dialogue with a range of stakeholders over the past decade, fuelled in part by the development of a 'soft' competence in sport in Article 165 of the Treaty of Lisbon which came into effect in December 2009. This paper traces the nature of the European Union's interest in this policy issue and in particular the rationale for, and the manner of, EU involvement.

Two principal rationales exist for the protection of athletes' access to education and vocational training, namely (a) a rights-based discourse in which athletes are seen to be denied access to education and vocational training which are protected for other workers or citizens; and (b) a performance-based discourse in which the athlete's ability to perform in athletic terms is enhanced by virtue of their access to educational opportunities. The paper reviews the relevance of these two rationales, and argues that although the EU engagement with dual careers might rest not on a sports competence but on prior competences relating to workers' rights and the protection of minors, the identifying of a performance rationale for supporting dual careers may be important in terms of engaging coaches and administrators

\section{Introduction}

One of the growing concerns of governments and the sports movement in general in the period since the beginning of the century has been the impact of the increasing demands of international elite sporting careers on the educational and vocational development of athletes, in particular the young. This is reflected, for example, in the efforts of the IOC to promote athlete career programmes [1] and in various national systems such as the educational and vocational elements of the UK Sport Performance Lifestyle programme [2], as well as in the academic literature on athlete transitions [311] which tends to focus primarily on the transition from an athletic to a post-athletic career and the factors which are associated with successful transition $[12,13]$. The concerns of stakeholders such as government on the one hand with maintaining athletes' right of access to education, and work during and subsequent to elite sport careers, is complemented by those of other stakeholders (e.g. coaches and National Sports Federations) who acknowledge that for many athletes meeting concerns about their post-athletic or current study and vocational training needs may well have a positive impact on sports performance whilst they are still engaged at the elite level, allowing 
athletes to be more focused on sporting performance. Thus for some stakeholders there is an athletes' rights perspective on the provision of dual career opportunities while for others there is a sports performance rationale. This paper focuses however on the policy rationales developing in one newly emerging stakeholder in this field, the European Union (EU) following on from the adoption of the Treaty of Lisbon and its incorporation of a competence for the EU in sport. The growing importance of this area of policy is one which has been accelerated by the Treaty on European Union which came into force in December 2009[14, 15].

In fact prior to the Lisbon Treaty coming into force, though the EU did not have a legal competence to legitimate policy action in the sport domain of and for itself, it did impinge very significantly on sport because concern with sport overlapped with other policy areas in which the EU had already a legal role to play.

Sport [had] become associated not only with free movement and competition laws but also with a large number of other EU policy areas including, public health, education, training, youth, equal opportunities, employment, environment, media and culture. [16]

In particular its policy concern with youth and with employment, education and training had led to an increasing concern to address the broad policy issues of athlete access to education and training, and this is reflected in a number of research studies commissioned since 2000 [e.g. 17], and which have subsequently resulted in the drafting of EU Guidelines on Dual Careers of Athletes:

Recommended Policy Actions in Support of Dual Careers in High-Performance Sport [18, 19]. The aim of this article is to trace the nature of the policy concern with athletes' rights in relation to access to education, and to identify in particular the rationale and approach adopted by the European Union in promoting policy in this area. The structure of the article progresses through a discussion of the ways in which these commissioned studies, the EU White Paper on Sport [19] and the EU Guidelines have progressed the policy debate and concludes with a discussion as to the rationale for EU involvement in policy in this field.

\section{The History of EU Involvement in the Dual (Educational / Vocational and Sporting) Careers of Young Elite Athletes}

Perhaps the first formal consideration of the issues involved in the impact of elite sport participation on access to educational and vocational opportunities was reflected in a working paper presented to the European Parliament in 2003 which reported the situation within Member States in respect of the provision for elite athletes under seven headings relating to education, employment, financial support and pensions.

This working paper provided a brief descriptive overview of the range of arrangements made in 14 Member States and its findings are summarised in Table 1 below. It was followed by a more detailed study of the 25 Member States (subsequent to expansion of the EU in 2004) which in addition to defining in more detail the nature of the measures adopted by Member States also sought to identify and differentiate the policy philosophies or rationales adopted by the different Members States for intervention in this field [15]. 
Table 1: Services to Athletes Available in Member States

\begin{tabular}{|c|c|c|c|c|c|c|c|}
\hline & $\begin{array}{l}\text { Provisions } \\
\text { for the } \\
\text { promotion } \\
\text { of athletes } \\
\text { within } \\
\text { education }\end{array}$ & $\begin{array}{l}\text { Quotas for } \\
\text { the } \\
\text { admission } \\
\text { of athletes } \\
\text { to university }\end{array}$ & $\begin{array}{l}\text { Grants for } \\
\text { retired } \\
\text { professional } \\
\text { athletes to } \\
\text { study at } \\
\text { university }\end{array}$ & $\begin{array}{l}\text { Flexibility } \\
\text { within the } \\
\text { university } \\
\text { system }\end{array}$ & $\begin{array}{l}\text { Employm't } \\
\text { of athletes } \\
\text { in the public } \\
\text { sector } \\
\text { (police, } \\
\text { military etc.) }\end{array}$ & $\begin{array}{l}\text { Employm't } \\
\text { of retired } \\
\text { professional } \\
\text { athletes in } \\
\text { the private } \\
\text { sector }\end{array}$ & $\begin{array}{l}\text { The } \\
\text { existence } \\
\text { of a } \\
\text { pension } \\
\text { scheme for } \\
\text { athletes }\end{array}$ \\
\hline $\begin{array}{l}\text { Belgium } \\
\text { (French) }\end{array}$ & Yes & No & No & Yes & $N o^{1}$ & No & N/A \\
\hline $\begin{array}{l}\text { Belgium } \\
\text { (Flemish) }\end{array}$ & Yes & No & No & Yes & Yes & No & No \\
\hline Denmark & Yes & $\mathrm{No}^{2}$ & No & Yes & No & $\mathrm{No}^{3}$ & No \\
\hline Germany & Yes & No & Yes & Yes & Yes & Yes & No \\
\hline Greece & Yes & Yes & No & Yes & Yes & No & No \\
\hline Spain & Yes & Yes & No & Yes & Yes & Yes & Yes \\
\hline France & Yes & No & Yes & Yes & Yes & Yes & Yes \\
\hline Ireland & Yes & No & No & Yes & No & No & $\mathrm{No}^{4}$ \\
\hline Italy & Yes & No & No & $\mathrm{No}^{5}$ & No & Yes & Yes \\
\hline Luxembourg & Yes & No & No & No & Yes & No & No \\
\hline $\begin{array}{l}\text { The } \\
\text { Netherlands }\end{array}$ & Yes & No & No & Yes & Yes & No & Yes \\
\hline Austria & Yes & No & No & No & No & No & No \\
\hline Finland & Yes & No & Yes & Yes & No & No & Yes \\
\hline Sweden & Yes & No & No & No & No & No & No \\
\hline UK (England) & Yes & No & No & Yes & No & $\mathrm{No}^{6}$ & No \\
\hline $\begin{array}{l}\text { UK } \\
\text { (Northern } \\
\text { Ireland) }\end{array}$ & Yes & No & No & Yes & No & No & No \\
\hline $\begin{array}{l}\text { UK } \\
\text { (Scotland) }\end{array}$ & Yes & No & No & Yes & No & $\mathrm{No}^{7}$ & No \\
\hline UK (Wales) & Yes & No & Yes & Yes & No & $\mathrm{No}^{6}$ & No \\
\hline
\end{tabular}

${ }^{1}$ The government of the French-speaking Community takes on 15 high-level athletes each year so they can concentrate fully on their sports activities.

2 Although quotas do not exist, a sports career is considered as a valid qualification for certain courses

${ }^{3}$ Although private companies are not offered direct incentives, one of the sponsors of Team Denmark is an employment agency which aims to provide employment opportunities to athletes.

${ }^{4}$ However employees in the sports sector enjoy favourable conditions regarding pension contributions.

${ }^{5}$ Officially flexible arrangements for athletes are possible only at certain private universities and otherwise can be difficult to negotiate.

6 However the OPEN programme seeks to encourage private companies to employ athletes.

7 However the Scottish Institute for Sports works to help current professionals gain employment.

(Source: Adapted from European Parliament, 2003: p. 63)

Thus, an important goal of this 2004 study was to characterise and categorise the kinds of roles in which European Union Member State governments cast themselves in this field. The findings underlined the fact that not all national systems acknowledge the growing need to respond to the demands placed on elite young sportspersons. Forms of provision for student-athletes vary from the 
negligible to established structures backed by legislation. The analysis of the types of response evident in the 25 European Member States can be summarised in a typology which is cited below (with two examples of Member States for each type to illustrate the role of the state vis a vis other actors).

\section{The Roles of Member States in the European Union in Providing or Facilitating Opportunities for Student-Athletes in Higher Education}

The review of the approaches evidenced in the EU identified four principal types of approach. These were ideal types and thus individual cases may manifest aspects of more than one type. However the typology provides a useful way of conceptualising different approaches from highly interventionist to virtual laisser faire, and each of these provides a different kind of response to the question of athletes' rights in the domain of education.

\subsection{Type 1: State-centric System of Defined Legal Obligation}

The first type of approach is one in which a legal requirement is placed on universities to provide adapted opportunities for student-athletes. (Examples include France, Hungary, Luxembourg, Spain, Poland and Portugal).

\section{Hungary}

In the case of Hungary the state had adopted legislation facilitating entry requirements for elite athletes. In accordance with a governmental decree (246/2003. [XII.18.] on the General Regulations of Admission Procedures at higher education institutions Olympic medallists were given the right to be admitted to any colleges/university without an entrance examination. In addition, in accordance with the same ministerial degree, during the allocation of points in the admission process five bonus points were to be given to those athletes in medal places in world and European championships (though only in Olympic sports) and three bonus points given to winners and those placed second or third in national championships held in any Olympic sports (again exclusively in Olympic sports).

Furthermore institutions offered exemption or reduction of tuition fees. Under the Course for Life Programme launched in 2002 universities contracted to exempt one to three gifted young sportsmen/sportswomen recommended by the HOC, from paying tuition fees and to reduce the fees in respect of other young sportspersons' tuition.

Universities also offer elite athletes flexibility in relation to student athlete absence, and their study and examination timetable. These arrangements apply only to young sportspersons who are beneficiaries of the agreement between the $\mathrm{HOC}$ and colleges/universities. These student athletes have the opportunity to pursue their studies according to individual study and examination timetables.

Finally monitoring of, and tutorial assistance for, elite athletes in respect of academic studies is provided. Study activities are scheduled to accommodate the needs of training and competition, textbooks, handbooks, manuals, special literature and other auxiliary educational materials are provided with the aim of promoting the opportunity to study during periods of absence for training or competition. 
In the Spanish case also there is legislation (Royal Decree 1467/1997, 19 September) requiring universities to reserve $3 \%$ of the total places provided for accredited high performance sportsmen and women who have at least the minimum academic requirements. In addition the institutions which provide degrees in the area of Physical Activity and Sport Studies, and the National Institutes of Physical Education are required by law to reserve an additional number (equivalent to $5 \%$ of their intake) of places for high performance sportsmen and women. Additionally services including individual tutor monitoring, reserving of places in university residences, flexible timetables and flexible schedules for the sitting of exams are offered to student-athletes.

Some universities and higher education institutions provide additional student athlete support. The University of Oviedo for example in $\mathbf{2 0 0 4}$ had 50 élite student-athletes at the university, most of whom were granted: registration scholarships; their own scholarship of the University of Oviedo; and, where necessary, a scholarship for accommodation in a Hall of Residence. They also received an allocation of free elective credits applied to the academic programme they are studying, designed for athletes.

\subsection{State Sponsored Formal System Established on Permissive Legislation}

The second type of approach is one in which there is a formal system for acknowledging studentathletes' needs, which stops short of a legal requirement but where permissive legislation or regulations exist, authorising but not requiring universities to make special provision for elite sportspersons. (Examples here include Belgium (Flanders), Denmark, Estonia, Finland, Germany, Latvia, Lithuania, Sweden.)

\section{Belgium (Flanders)}

Unlike the examples of Hungary and Spain, in which state legislation requires certain types of response the state sponsored approach involves the development of permissive legislation and / or formal agreements between the state and selected educational institutions. Such an approach is exemplified by the Flemish Community of Belgium which in 2003 introduced an agreement, the Topsportconvenant, which was initiated by the Ministry of Sport of the Flemish Community in cooperation with the three independent educational networks, the Belgian Olympic and Inter-federal Committee (BOIC) and the sports administration body (BLOSO) of the Flemish community.

The Topsportconvenant introduced two initiatives aimed at supporting young sportspersons in higher education. Firstly, for the academic year 2003/04, the sports governing administration BLOSO and the Belgian Olympic and Inter-federal Committee awarded those student-athletes who were ranked on the Olympic lists, a contract ( $70 \%$ of a full-time professional contract) which allowed them to combine élite sport and studies in higher education. This included a scholarship of $€ 20,000$ enabling these student-athletes to pay for specific costs incurred in combining élite sport and study as well as sport-specific support The scheme started with modest numbers. In the first year of operation, five student-athletes were awarded a contract - four in higher education outside of the university system and one university student (at the Vrije Universiteit Brussel).

The second initiative began in the 2004/05 academic year and was targeted at young Olympic athletes selected for the Belgian Youth Olympic Team who registered at a university or other higher education. In the first years of operation 20-30 young Olympic athletes were to be eligible for 
support. Unlike the athletes on the official Belgian Olympic ranking list the members of the Youth Olympic team were not awarded contracts, but received financial support allowing them to combine higher education and élite sport.

The Vrije Universiteit Brussel was the first higher education institution to respond to these initiatives, developing its 'Study and Talent Education Programme' (STEP) to provide complementary services for élite student-athletes. STEP included workshops and presentations on time-management, communication skills, financial management, injury prevention and rehabilitation. In addition student athletes could request to spread the work of one academic year over an extended time period (two, three or four years longer). This request has to be made to the institution upon registration. Flexibility may also be offered to student athletes in regard to exam timetables.

\section{Germany}

In the case of Germany a contract between the Deutscher Sportbund, National Sport Federations, the University Sports Association and higher education institutions allows student-athletes attending one of the 48 élite sports universities to have access to a range of services and benefits. These include reduced entry criteria for athletes; flexible timetabling; flexible examination timetable; alternative means of completing course requirements such as discretion and flexibility for attendance at compulsory seminars/lectures; and tutor monitoring, with students offered personal tutors and study counselling. It was estimated that approximately 850 national squad members (C, B and A-squads) are enrolled at these universities at any one time.

In addition the German Sports Aid Foundation offers temporary bursaries of up to three years to professional athletes who have enrolled on a university programme and then retire from competitive sport.

\subsection{Representation of Athletes Educational Interests by Sporting bodies}

The third type of approach is one in which the athletic development needs of the individual are catered for by the sporting institutions and where sporting advocates act on behalf of the student, to negotiate flexible arrangements with the university.

\section{Greece}

Greece is an example of a state which provides some limited rights to student-athletes, and thus exhibits some features of the previous type, but which ultimately relies on negotiation between the athlete, or National Sport Federation staff or coaches acting on behalf of the student-athlete, and university staff to facilitate athletes' completion of their academic programme. Athletes with distinguished sporting performance can be given exemption from entrance examinations to any university department of their choice (with no limits on the number of the athletes admitted to each department). For national champions at senior or youth / junior level entry can be offered to one of the five Departments of Physical Education and Sport Sciences (up to $30 \%$ of the total admission number of the department) (Ministry of Sport, Law 2725/1999).

The government also offers two types of scholarship. The first is an annual scholarship for students of any educational level up to undergraduate studies. The second supports athletes for graduate 
studies at Greek Universities or abroad, in sport related disciplines (Deputy Ministry of Sport, Law 2725/1999)[20].

Student-athletes in Greek universities are permitted to maintain their student status for an unlimited length of time, irrespective of their academic achievement. Thus a student may remain registered as a candidate for a bachelor's degree for 8 or 10 years. This allows élite athletes to set aside their studies to train intensively and take part in competition. At the end of their sporting career the athlete can return to his / her university to complete his / her studies. Such an approach is not without difficulties since returning to academic studies periodically after extended absence can prove problematic.

However although these measures were in place, in practice flexibility in study arrangements, outside of sports science departments could be difficult to implement. Special treatment is a matter of personal negotiation with the hosting department and not all are sympathetic. Athletes report having had to rely on the intercession of their coaches or their National Federations with the university and that this had proved to be of variable effectiveness.

\section{United Kingdom}

A number of universities in the UK have traditionally informally offered elite student-athletes special concessions in terms of exam dates, location for holding examinations, assignment deadlines, waiving of attendance requirements and flexible duration of programmes of study. However at the elite level those athletes on the UK Sport World Class Performance Programme have access to the services of a 'Performance Lifestyle Advisor' employed by one of the National Institutes of Sport in the UK, and where necessary this individual will negotiate directly with teaching staff on behalf of the student-athlete.

While the UK system has thus traditionally had an informal element of negotiation (often by the National Sports Federation or the Performance Lifestyle Advisor) as preparations for the hosting of the London 2012 Games intensified, government activity in this area had increased since the 2004 survey.

The Talented Athlete Scholarship Scheme (TASS) introduced in 2004 has been further formalised and extended. This scheme serves athletes below the World Class Performance Programme. The programme provides government funding which is designed to promote a partnership between NGBs and Higher Education / Further Education institutions. Its stated aims are to promote a balance between academic life and training as a performance athlete, thus reducing the drop-out of talented athletes from sport due to academic and financial pressures. The focus is thus on maintaining sporting performance and the scholarships which amount to up to $£ 3,500$ per year are generally intended for supporting sporting expenditure on services such as coaching, physiotherapy, sports science, nutritional advice, and sports psychology, rather than on educational services or materials.

An addition to the TASS scheme in 2009 were TASS 2012 scholarships aimed at those with potential to progress towards the World Class Performance Programme. This provides annual grants of up to f10k but again these are intended for sports support services rather than educational services. Nevertheless TASS advisors may negotiate with university staff on behalf of their student-athletes to achieve some flexibility in requirements. 
The top tier of elite athletes on the World Class Performance Programme (WCPP) receive the services of a Performance Lifestyle Advisor who will provide advice and support for all non-sporting aspects of lifestyle including educational and vocational preparation support. The WCPP is divided in to three categories of athlete, namely 'Podium', those with genuine potential to win Olympic / World Championship medals; 'Development', those who will be competitive for medals in 2016; and 'Talented', athletes identified as those likely to progress through the World Class pathway. 1200 athletes in the top two categories have benefited from government investment of $f 100 \mathrm{~m}$. per year for sports performance support.

\section{4: Type 4 'Laisser-faire' - No Formal Structures}

The fourth approach is one where there are few or no formal structures and any arrangements fall back on individually negotiated agreements where these prove possible. This category is very broad because there are institutions that have been very proactive in accommodating student-athlete needs such as some institutions in The Netherlands and Cyprus but there are also those countries whose systems have traditionally been quite rigid in nature in relation to student-athletes' needs such as Italy and Malta. (Other examples in this type include Austria, Czech Republic, Ireland, Slovakia, and Slovenia.)

\section{$\underline{\text { Italy }}$}

The system of sport education in Italy changed at the end of the 1990s. In the old system there had been 15 Institutes of Physical Education, while at the time of the fieldwork there were approximately 30 universities offering sport related courses. Most of these courses were provided within Faculties of Medicine, which have tended to be conservative in terms of allowing adaptations to courses, assessment or attendance requirements to be made for athletes or other groups.

Flexibility of course requirements for student-athletes is more apparent in some private universities, but in the public universities requirements can be rigid and any request for flexibility is seen as a matter between the student-athlete and teaching staff.

Some of the Universities do have links with sport federations but these are not particularly strong or consistent, and although some sport federations give out bursaries to student-athletes to further their education at universities, this practices is limited. Student-athletes may, however, negotiate individually with university staff.

\section{Malta}

Malta is perhaps typical of a number of micro-states. It has a small education system (including a single university). With a small university system it is perhaps more difficult to adapt provision to accommodate the needs of athletes. Sporting excellence and the needs of athletes are thus not acknowledged at the university or at any other academic institution. The only concession that is offered came into effect in 2003 when young athletes participating in international competitions were given the opportunity to postpone their university exams.

As is evident from the above commentary each of the approaches described carries with it costs and benefits in terms of meeting the educational and sporting needs of young student-athletes. However before going on to consider these costs and benefits in relation to the implications of these 
approaches for consideration of the roles, rights and responsibilities of stakeholders, we will consider the issue of educational provision for student-athletes who are members of the player academies of professional sports clubs.

\section{Relationships between the State and Professional Sport Academies in Relation to Athlete Education.}

In the same way as the relationship between the state and educational institutions in respect of athletes rights ranges along a continuum from direct intervention to laisser faire, so in the case of the nature of government control of professional sporting academies, there is a range of approaches. In Italy, for example, government offers very little monitoring or control of professional sporting entities in terms of the delivery of educational opportunities. In the UK however, in 2003, Skills Active (which is the Sector Skills Council [21] ${ }^{i}$ responsible for sport and fitness) developed a qualification, the Advanced Apprenticeship in Sporting Excellence (AASE) , a programme of study and qualification designed to meet the needs of athletes who are training professionally in, for example professional football or rugby academies, as well as those training intensively in other sports, disrupting their access to mainstream schooling [22]. However engagement with the apprenticeship scheme is voluntary rather than mandatory for sports or particular clubs, and the provision of a single programme at a particular level is unlikely to provide a good 'fit' given the range of educational / vocational training needs in this disparate population.

In the case of France however Olivier Nier [23], in an unpublished report for the 2004 study highlighted ways in which the French state promotes good practice in the field of professional academies by using a system of individual contracts between young players and their club / academy with financial sanctions for failing to achieve the contracted goals agreed. It is worth highlighting Nier's account of the case of the academies of professional French rugby clubs in some detail.

Using data from the early 2000s he seeks to illustrate how the clubs were more effectively influenced to commit themselves seriously to helping players to set and achieve realistic and meaningful educational goals. Academy players represent a marginal playing resource. Of the 379 Academy Players registered at professional clubs in the top two divisions in 2003/4: 62 played for the professional team during the season; an average of 3 players per Academy / Training Centre, playing an average of 15 Matches; with 47 (12\% of academy players) gaining professional contracts at the end of the season. This highlights the importance of two contributions of the Academies / Training Centres: first their financial contribution to the professional clubs, since players in the academy are used without seriously impinging on the salary costs; and secondly the importance of the educational contribution to the players which is particularly crucial for the $88 \%$ who do not receive professional rugby contracts.

The economics of professional rugby in France make the financial contribution potentially critical. Although TV rights income grew by $46 \%$ from $1998-2007$ (from $€ 55.7 \mathrm{~m}$. to $€ 78.2 \mathrm{~m}$ ); In the top division (Top 16) club expenditure grew by 56\% in the period from 1998 to 2003 alone (€2.13 m. to $€ 3.32 \mathrm{~m}$.); and players' salaries grew by 70\% 1998-2001 (€2200 - €3800 per month) so that by 2002 salaries represented $58 \%$ of all club expenditure. The State Auditor however imposed a limit of $60 \%$ as the proportion of club expenditure which could be allocated to salaries. Thus although academy 
players were a marginal playing resource they were cheap, and could make the difference in terms of not going over budget.

A significant source of income to the club was government grant tied to performance in respect of each academy player. At the beginning of the year the education officer agrees a set of goals with each player. This may be achievement of an end qualification, or progression in the system (e.g. from year 1 to year 2 of an undergraduate programme). Figure 1 indicates the range of qualifications sought by academy players in 2003/4 (which is much wider than the single Advanced Apprenticeship scheme delivered in most cases to academy players in football and rugby academies in England). However, unless the players meet their educational goals - the club loses $90 \%$ of its funding for a player's education. The net result is that clubs are much more likely to be concerned about academic performance since failure to perform results in financial penalties, and the standard of academic performance in a much wider range of qualifications, though far from perfect, is impressive compared with the English case, where educational performance has been traditionally poor in football academies in particular (see Figure 2).

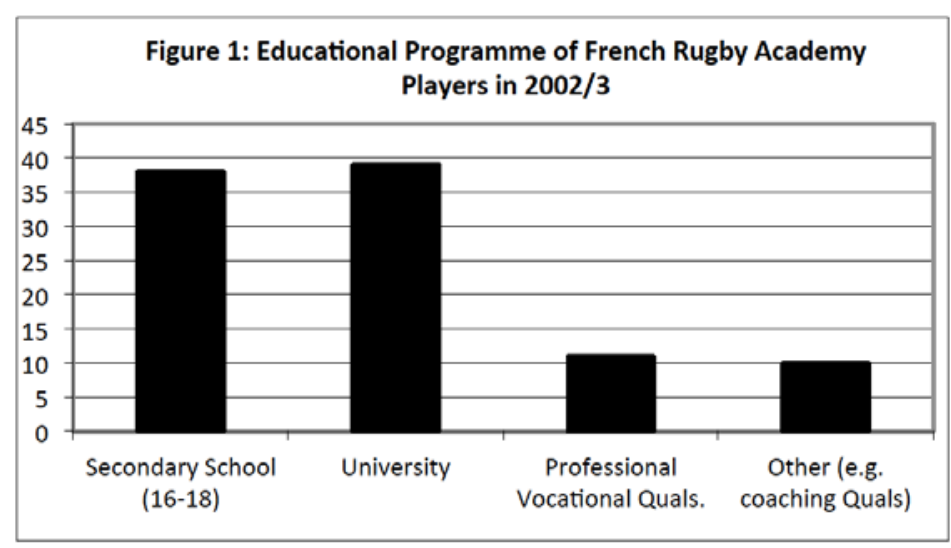

Source: Nier (2004)

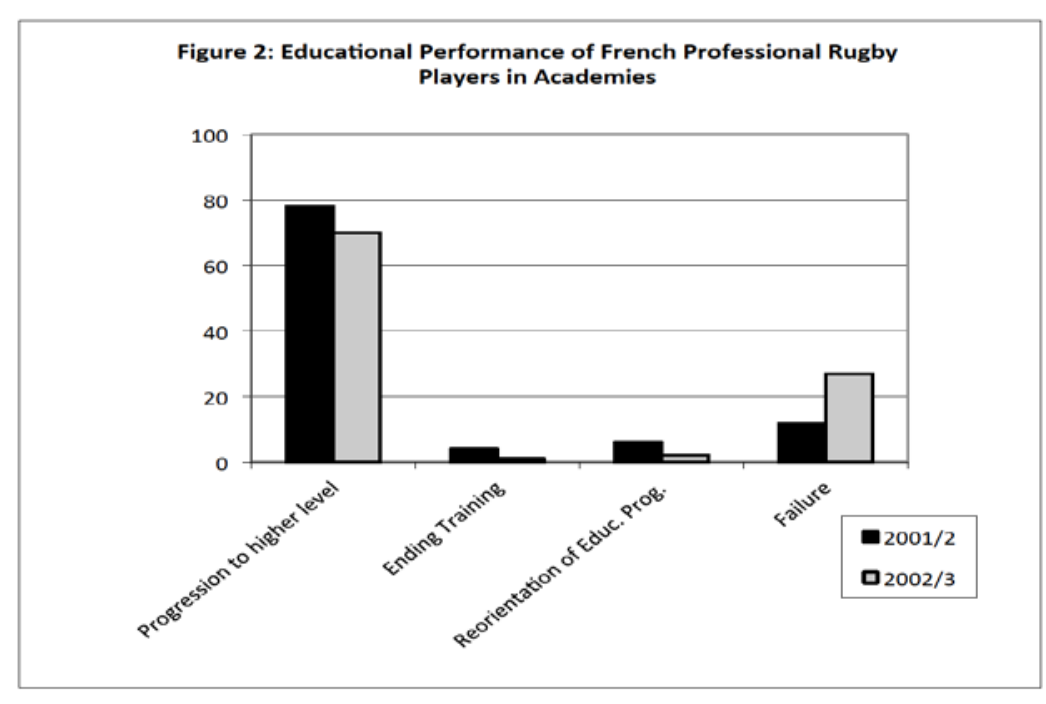




\section{The EU White paper on Sport 2007 and commissioning of the INEUM Consulting / TAJ Study on training of young sportsmen/women in Europe}

Following the 2004 Study, the EU Sport Unit's priorities were driven by the preparations for inclusion of an article on sport in the new Constitution for Europe signed in 2004 and ratified in 2005 by 18 Member States (but later abandoned after referenda in France and the Netherlands rejected the Treaty), and the subsequent adoption of the Treaty of Lisbon in 2007, coming into force in December 2009. These preparations included a White Paper on Sport, and the commissioning of a new study on training systems for young people in sport in the EU.

While the White Paper predated the coming into force of the new Treaty with its article incorporating a sports competence, it nevertheless signalled the continued prioritising of policy development in this area, and makes explicit the European Commission's twin concerns which relate to insertion in the labour market at the end of elite sports careers, and the treatment of athletes, particularly the young, within training centres.

In order to ensure the reintegration of professional sportspersons into the labour market at the end of their sporting careers, the Commission emphasises the importance of taking into account at an early stage the need to provide "dual career" training for young sportsmen and sportswomen and to provide high quality local training centres to safeguard their moral, educational and professional interests [25]

The study of the training systems in Europe investigated 15 sports practised throughout Europe reflecting the variety of sports (amateur / professional, individual / team, summer / winter, etc.), and the gender predominance and sports practiced by disabled persons were considered. The study incorporated a typological description of the different mechanisms and systems for the training of young athletes, and analysis of quality criteria applied youth elite sports training systems, together with national and European legal and political frameworks relating to the training of young athletes.

In relation to the typology of mechanisms and systems for sports training, the authors identify a number of factors that impact on the nature of provision for education by individual sport. These include: whether the sport is professional; a team or individual sport; is a sport with early / middle / late 'maturity' in terms of the age of athletes at the onset of intensive training and of elite competition; the system of training centres; and the specific rules and quality standards in respect of athlete education which are required by the state or by the sports federation.

The following figure illustrates the factors influencing the point at which the athlete's schooling is interrupted. 


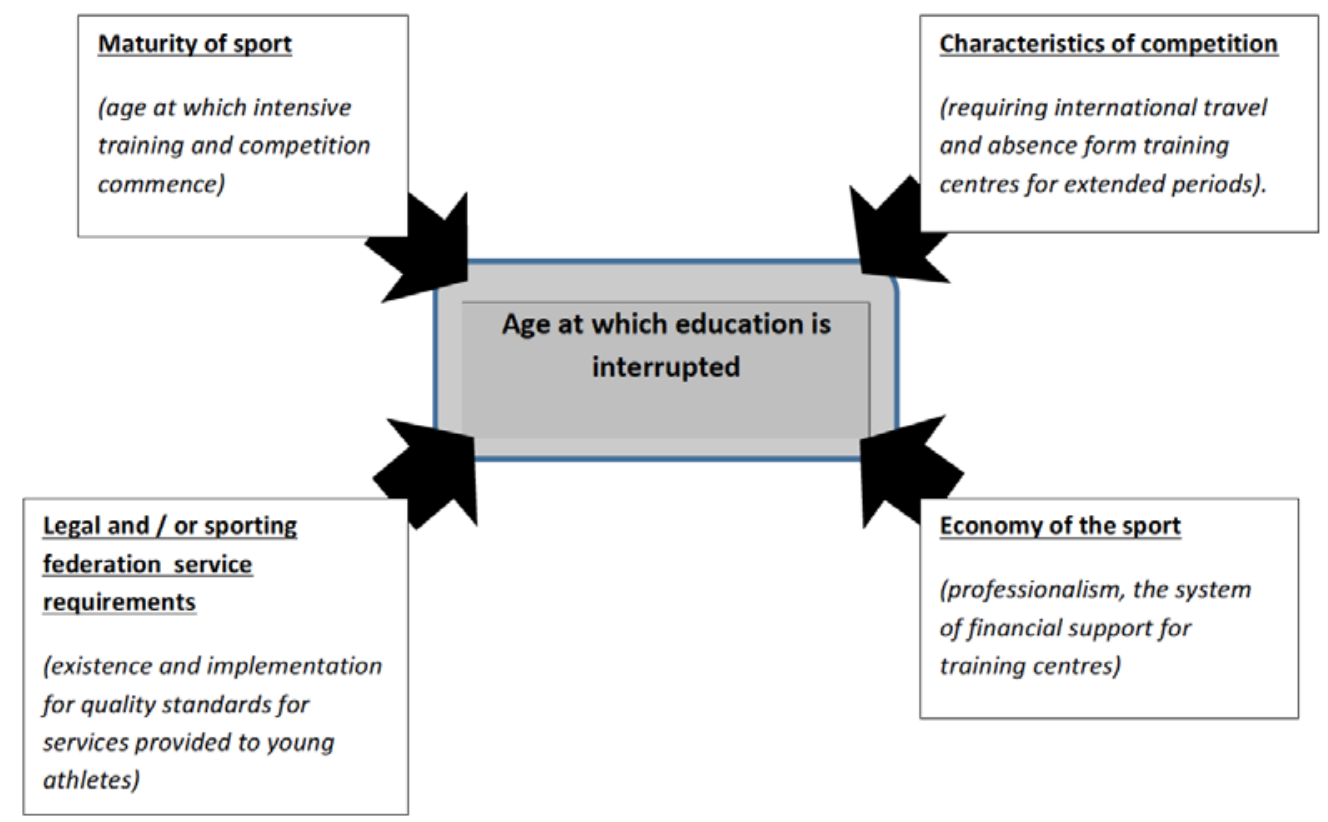

Source: adapted from INEUM, 2007: p. 40.

The report goes on to identify the level of disruption of education evident for different sports, differentiating professional team sports, individual professional sports and 'non-professional' sports. For professional team sports, football usually involves signing a full professional contract at 18 , and thus education beyond this age is extremely rare. Basketball follows a similar pattern, while for rugby the critical age appears to be 21 , though greater flexibility appears to exist in this case. In terms of individual sports, tennis requires intensive development from an earlier age, and is a sport which is highly developed in financial terms and the age of termination of studies tends to be 16 or less. Cycling reports problems in those countries such as Belgium which have a strong tradition, with young athletes despite the existence of 'Top Sport' schools, finding it increasingly difficult to combine high school study and sports training. In relation to non-professional sports, athletics and swimming represent sports where very few athletes can live from their sporting earnings and education and sporting preparation can be combined.

Of course within the same sport differences between different Member States exist as a result of varying approaches to legal protection of access to education (as exemplified in the discussion above of the French rugby system, and the INEUM report concurs with the conclusions of Amara et al. (2004) that the EU has a significant role to play in protecting young athletes interests in this field.

\section{The Establishing of EU Guidelines in respect of Athletes' Dual Careers.}

The series of reports commissioned by the Sports Unit of the European Commission, together with work undertaken by other interested stakeholders [25] led to the drafting of a set of 36 recommended guidelines on dual careers [26]. Given that the competence provided by the Lisbon 
Treaty in respect of sport was a shared (or 'soft') competence, one in which the EU was not given primacy over national policy and legislation, it is not surprising that the guidelines produced take the form largely of exhortation and encouragement of public authorities and other stakeholders such as training centres, educational institutions and sporting bodies to work together to develop and sustain measures which will promote dual career opportunities.

Six of the 36 guidelines however do relate directly to the role which the European Commission might play. We have argued elsewhere that the responsibilities of the EU in relation to dual careers are those of "Enhancing the knowledge base of Member States and highlighting inequities; protection of the individual's rights against the Member State (ECJ)" [27]. In particular the role of the Commission relates not to the activities of individual states (except in terms of exhortation), but to transnational activity. Thus the six guidelines directly related to the European Commission focus on the following transnational contributions:

- Stimulating cooperation between national training centres and educational institutes from different Member States in order to support the development and availability of dual career policies for student-athletes from other Member States (Guideline 27)

- creating opportunities within its programme for education and training to provide financial and organisational support for the development and implementation of dual career mobility networks of cooperating sports organisations and educational institutes on behalf of student-athletes who move from one Member State to another. (Guideline 28)

- encouraging and supporting the leading educational institutions and universities in Member States, in partnership with sport stakeholders, to participate in transnational consortia to develop shared curricula and educational programmes for elite sportspersons. Such programmes could involve common degree programmes, common modules within degree programmes, or shared curriculum resources. (Guideline 29)

- supporting European dual career networks bringing together stakeholders representing athletes, sports organisations, educational institutions, supporting services, national authorities, coaches and businesses, in order to further the dissemination and implementation of these Guidelines. (Guideline 33)

- supporting research regarding the international dimension of dual career programmes, in particular regarding the effects of transitions in athletes' lives, the safeguarding of the development of young athletes in early specialisation sports, the effectiveness of measures and supporting services in the Member States, and the re-entry process of European athletes into the labour market. (Guideline 35)

- monitoring key developments in the field of dual careers of athletes at national and European level and to evaluate the implementation of these Guidelines. (Guideline 36)

\section{The Development of a Second Rationale for Protecting Athletes' Access to Education.}

It is clear from the above discussion tracing the development of EU policy thinking in relation to this issue that the concern to protect access to education (and other aspects of a dual career) has been associated with a discourse relating to athletes' rights in a situation in which athletes may be pressured to act against their long term economic and employment interests. Coaches may resist the protection of athletes' rights in this area where they feel that focusing on education will distract an 
athlete and lead to sub-optimal performance. However while the pursuit of goals in two different fields at the same time might be regarded by some as at best a compromise, and at worst as generating conflicting priorities which undermine performance in both education and elite sport, there is also some evidence that these dual priorities can be not simply mutually compatible but indeed complementary.

In research which followed on from the 2004 study by Amara, Aquilina, Henry et al., Aquilina [28] sought to address this issue by investigating sporting and educational experiences of elite performers who were or had been university students, drawn from three European countries, France (an example of what the 2004 study had labelled a State-centric System of Defined Legal Obligation), Finland (a State Sponsored Formal System Established on Permissive Legislation), and the UK (an example of Representation of Athletes Educational Interests largely by Sporting Bodies). In each case, athletes (six per country) were selected, who were men and women drawn from Olympic and / or professionalised sports; were listed as elite athletes or were full time professionals; were at a career stage ranging from the beginning of their international career to immediate postretirement; were current or former students who had opted to study during their elite sport career; and who spoke English (in two cases with the aid of an interpreter). Aquilina sought to identify the nature of the athletes' experience of the two domains and how athletes negotiated the pressures resulting from both systems.

The research method adopted involved the taking of detailed life histories [29] which generated an extremely rich qualitative data set. It would not possible to do justice to this study in the limited space allotted here and so we restrict ourselves to highlighting a number of the themes which emerged from these 18 life histories.

Each of the elite sportspersons identified had chosen to enter into and remain within the education system so by definition this was a particular type of sample whose members one can regard as being positive about undertaking education in tandem with their elite sport training. These three national systems were in effect chosen because of their differences. The state in France provides specialist institutions in particular INSEP ( $L$ 'Institut national du sport, de l'expertise et de la performance in Paris) to facilitate both sporting performance and educational / vocational preparation of athletes. In Finland permissive legislation allows for the support of athletes in a dual sporting-educational career, which together with state financial support permits elite athletes to continue their educational development. In the UK a system of financial support for sporting development is accompanied by 'local' arrangements made, particularly by universities specialising in sports science such as Loughborough and Bath Universities, to facilitate elite athletes' fulfilment of educational requirements. In all three systems athletes reported a positive attitude to the benefits of continuing with a dual education-sport career. Educational experience facilitated sporting development and skills developed in the sporting context were seen to be transferable to the worlds of education and of work.

The benefits cited included for example:

- The need to focus on more than one aspect of life which relieved the intensity of pressure emanating from both sport and from educational performance helping to 'put things in perspective'; 
- Belief that skills learned in one area were transferable and valued. Interviewees cited aspects such as: planning and organisation skills; team work; interpersonal skills; the ability to set goals, prioritise and monitor achievement; maintaining commitment; development of IT, numeracy and literacy, and analytical skills which can facilitate understanding and communication in coaching contexts; leadership; networking and business awareness;

- Frustration with the experience of having dedicated time exclusively to elite sport in the past, neglecting education, but which had resulted in minimal improvement in sporting performance;

- Intellectual stimulation to accompany the physical challenges of training and performance, helping to maintain interest and commitment;

- Simply performing better in sport in an academic environment which is sport-friendly;

- Feeling more secure and hence performing better with the 'safety net' of gaining appropriate qualifications, preparing for future life stages and in particular for post-athletic careers;

- A sense of 'balance' in recognising that there is more to life than sport, social comfort in mixing with peers.

Central to the concerns expressed in a range of issues raised by interviewees in the course of interviews was the question of 'balance', a concept not fully operationalised in the literature. Aquilina's approach to gaining some purchase on the relative importance or value placed on different life domains (sporting, education or work, and social) was to ask subjects to weight the value they placed on these life domains. This provides a simple but nevertheless suggestive set of responses. It is not clear whether respondents in their answers were referring to the value, as opposed to the time/effort, given to activities in these life domains. However, crude though these particular data are, they illustrate the relative weighting in terms of value or effort placed on sport as opposed to other areas of life. The notion of work-life balance was one which has gained a growing attention in the psychology and business literature since the late 1970s and is increasingly raised in relation to psycho-social health. It has begun to attract research attention in relation to the ways in which non-sporting activities impinge on sporting performance [26].

It seems clear that for some athletes at least, a significant factor in remaining focused on sporting goals had been the opportunity to balance sporting requirements with other demands or stimuli. In these 18 case studies of elite athletes who had chosen to go into higher education while pursuing their athletic career, education provision had for such athletes exerted a positive influence on sporting performance. It might be argued that a parallel study of athletes who had decided not to pursue a dual career track but had put their academic or vocational activities to one side while competing at the highest level, should be undertaken to establish the extent to which the single track approach adopted by those individuals impacted positively or negatively on their performance. For the type of athlete in Aquilina's sample however there was no tension between the dual careers, and in a number of instances this was recognised by their coaches as providing a significant gain in terms of performance. 
Table 2: The Perceived Sport-Education / Work-Social Life Balance of the Elite Athletes

\begin{tabular}{|c|c|c|c|c|c|c|c|c|c|c|}
\hline & \multirow[t]{2}{*}{ Athlete's sport } & \multirow[t]{2}{*}{ Age } & \multirow[t]{2}{*}{$\begin{array}{c}\text { Individual / } \\
\text { Team }\end{array}$} & \multirow[t]{2}{*}{$\begin{array}{l}\text { Male / } \\
\text { Female }\end{array}$} & \multirow[t]{2}{*}{$\begin{array}{c}\text { Early/ Late age } \\
\text { of } \\
\text { Specialisation }\end{array}$} & \multirow[t]{2}{*}{$\begin{array}{l}\text { Student / } \\
\text { Graduate }\end{array}$} & \multirow[t]{2}{*}{$\begin{array}{l}\text { Active / } \\
\text { Retired }\end{array}$} & \multicolumn{3}{|c|}{$\begin{array}{c}\text { Balance in Life: "How much } \\
\text { effort do you make / value do } \\
\text { you place on particular life } \\
\text { domains?" }\end{array}$} \\
\hline \multirow{7}{*}{ 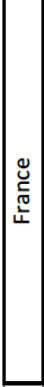 } & & & & & & & & Sport & Education & $\begin{array}{c}\text { Personal } \\
\text { /Social }\end{array}$ \\
\hline & Athletics & 28 & Individual & $\mathrm{F}$ & Late & Graduate & Active & $50 \%$ & $40 \%$ (job) & $10 \%$ \\
\hline & Badminton & 31 & $\begin{array}{c}\text { Individual / } \\
\text { Team }\end{array}$ & $M$ & Late & Student & Active & $30 \%$ & $30 \%$ & $40 \%$ \\
\hline & Handball & 21 & Team & $\mathrm{M}$ & Late & Student & Active & $30 \%$ & $25 \%$ & $45 \%$ \\
\hline & Judo & 27 & Individual & $\mathrm{F}$ & Early & Graduate & Retired & $60 \%$ & $30 \%$ & $10 \%$ \\
\hline & Swimming & 22 & Individual & $M$ & Early & Student & Active & $60 \%$ & $10 \%$ & $30 \%$ \\
\hline & $\begin{array}{l}\text { Synchronised } \\
\text { Swimming }\end{array}$ & 20 & Team & $F$ & Early & Student & Active & $80 \%$ & \multicolumn{2}{|c|}{$20 \%$} \\
\hline \multirow{6}{*}{ 弚 } & Athletics & 23 & Individual & $\mathrm{F}$ & Late & Graduate & Active & $60 \%$ & $30 \%$ & $10 \%$ \\
\hline & Athletics & 23 & Individual & $\mathrm{F}$ & Late & Student & Active & $40 \%$ & $30 \%$ & $30 \%$ \\
\hline & Golf & 22 & Individual & $M$ & Late & Student & Active & $30 \%$ & $50 \%$ & $20 \%$ \\
\hline & Gymnastics & 22 & Team & $\mathrm{M}$ & Early & Student & Active & $80 \%$ & \multicolumn{2}{|c|}{$20 \%$} \\
\hline & Rugby & 22 & Team & $M$ & Late & Graduate & Active & $60 \%$ & $10 \%$ & $30 \%$ \\
\hline & Triathlon & 23 & Individual & $\mathrm{F}$ & Late & Student & Active & $35 \%$ & $35 \%$ & $30 \%$ \\
\hline \multirow{6}{*}{$\begin{array}{l}\frac{0}{C} \\
\frac{\pi}{c} \\
i \frac{1}{4}\end{array}$} & Athletics & 32 & Individual & $\mathrm{M}$ & Late & Student & Active & \multicolumn{3}{|c|}{ Unable to define } \\
\hline & Basketball & 28 & Team & $\mathrm{F}$ & Late & Graduate & Active & $30 \%$ & $\begin{array}{l}70 \% \\
\text { (job) }\end{array}$ & $0 \%$ \\
\hline & Football & 42 & Team & $\mathrm{M}$ & Late & Graduate & Retired & $30 \%$ & $60 \%$ & $10 \%$ \\
\hline & Gymnastics & 32 & Team & $M$ & Early & Student & Active & $40 \%$ & $30 \%$ & $30 \%$ \\
\hline & Ice-Hockey & 20 & Team & $\mathrm{F}$ & Late & Student & Active & $50 \%$ & $30 \%$ & $20 \%$ \\
\hline & Judo & 22 & Individual & $\mathrm{F}$ & Early & Student & Active & $70 \%$ & $25 \%$ & $5 \%$ \\
\hline
\end{tabular}

(Source: adopted from Aquilina, 2009: pp. 342-3)

What the results of this qualitative study suggest is that even for some professional team sports (football in the case of a Finnish athlete, rugby in the case of a British athlete, and handball in the case of a French athlete) it was possible to pursue higher education options even though this has become increasingly unusual in soccer in particular (and more difficult in systems more commercialised than soccer in Finland). Some of the responsibility for failure of sports to provide appropriate educational opportunities to elite sportspersons is attributed to coaches and perhaps other stakeholders who regard engaging in any significant activity other than training as damaging to an athlete's potential to perform.

\section{Conclusions}

In this review we have traced the development of policy in the dual career domain and specifically the role of the EU. The rationale adopted at the EU level is one of human (athletes') rights and the protection in particular of minors. These rights have not been fully respected where for example coaches or other members of the athlete's entourage have placed pressure on the athlete to pursue sporting performance goals at the cost of prejudicing or even abandoning activities in the field of education or vocational preparation which (may) run counter to the athlete's long term interests. However, as Dawn Aquilina's study illustrates there is good evidence that for some (indeed when we view the number of current and former student athletes in Olympic teams for example, we can claim for many) athletes there is a positive rather than inverse relationship between educational opportunities and commitment, and sporting success. While this may not be the case for every athlete and the culture and practical contexts of certain sports may have traditionally militated against accommodating education and vocational training, there is a good argument for suggesting that the mutually reinforcing relationship between education and sports performance is an aspect 
which could be more fully addressed in coach education. Although the rationale for EU intervention in this field may be rights-based, support for a research base to highlight, not simply the longer term costs of failing to promote educational and vocational opportunities, but also the conditions under which mutual reinforcement of these goals aims achieved, is an area in which policy intervention should be welcomed.

\section{Endnotes}

1. Adecco. International Olympic Committee Athlete Career Programme in cooperation with Adecco Group. In: Adecco; 2008.

2. UK Sport. Performance Lifestyle. In. London: UK Sport; 2012.

3. Brewer B, Van Raalte J, Petitpas A. Self-Identity Issues in Sport Career Transitions. In: Career Transitions in Sport: International Perspectives. Edited by Lavallee D, Wylleman, P.,: Fitness Information Technology; 2000. pp. 29-43.

4. Dacyshyn A. When the balance is gone: the sport and retirement experiences of elite female gymnasts. In: Inside Sports. Edited by Coakley J, Donnelly, P.,: Routledge; 1999. pp. 214-222.

5. De Knop P, Wylleman P, Van Hoecke J, De Martalaer K, Bollaert L. A European Approach to the management of the combination of academics and elite-level sport. Perspectives: The Interdisciplinary series of Physical Education and Sport Science: School Sports and Competition 1999,1:49-62.

6. Lavallee $D$, Robinson, $H_{\text {.,. }}$ In pursuit of an identity: A qualitative exploration of retirement from women's artistic gymnastics. Psychology of Sport and Exercise 2007:119-141.

7. North J, Lavallee D. An investigation of potential users of career transition services in the United Kingdom. Psychology of Sport and Exercise 2004:77-84.

8. Stambulova N. Athlete's Crises: A Developmental Perspective. International Journal of Sport Psychology 2000:584-601.

9. Stambulova N, Stephan $\mathrm{Y}$, Japhag U. Athletic retirement: A cross-national comparison of elite French and Swedish athletes. Psychology of Sport and Exercise 2007:101-118.

10. Wylleman P, Lavallee D. A developmental Perspective on transitions faced by athletes. In: Developmental Sport and Exercise Psychology: A lifespan perspective. Edited by Weiss M: Fitness Information Technology; 2004. pp. 503-523.

11. Yannick S, Bilard J, Ninot G, Delignieres D. Repurcussions of Transition out of elite sport on subjective well-being: A one-year study. Journal of Applied Sport Psychology 2003:354-371.

12. Lavallee D. The Effect of a life development intervention on Sports career transition adjustment. The Sport Psychologist 2005:193-202.

13. Wylleman P, Alfermann D, Lavallee D. Career transitions in sport: European Perspectives. Psychology of Sport and Exercise 2004:7-20.

14. The author' role as observer of the developing policy concern by the EU in this area has been directly informed by his involvement as principal investigator in the Amara, Aquilina, Henry and PMP (2004) study, as a contributor to the INEUM (2007) study and as a member of the European Commission's Ad Hoc Expert Group that worked on the drafting of the EU Guidelines on Dual Careers.

15. Aspects of this paper (in particular sections three, four and seven) draw on an unpublished position paper to the IOC Olympic Studies Centre, Henry, I (2011) 'Elite Athletes and Higher Education: Lifestyle, 'Balance' and the Management of Sporting and Educational Performance.' http://doc.rero.ch/Im.php?url=1000,42,38,20110314150728-YK/2010__Henry.pdf

16. European Commission. The Lisbon Treaty and EU Sports Policy. In. Brussels: Directorate General for Internal Policies: Policy Department B: Structural and Cohesion Policies; 2010: p.3. 
17. The following three reports represent the major studies concerned: Amara $M$, Aquilina $D$, Henry I, PMP Consultants. Education of Elite Young Sportspersons in Europe. In: Studies on Education and Sport. Brussels: European Commission: DG Education and Culture; 2004. pp. 345; European Parliament. Combining Sport and Education: Support for athletes in the EU Member States. In: Education and Culture Series, EDUC 114EN. Luxembourg: European Parliament; 2003; INEUM Consulting, TAJ. Study on the training of young sportsmen and sportswomen in Europe. In. Brussels: European Commission; 2007.

18. European Commission. EU Guidelines on Dual Careers of Athletes: Recommended Policy Actions in Support of Dual Careers in High-Performance Sport (Approved by the EU Expert Group "Education \& Training in Sport" at its meeting in Poznań on 28 September 2012, forwarded for approval by the Council of Ministers and published on the ENGSO web site). In. Brussels: Sport Unit, European Commission; 2012.

19. European Commission. White Paper on Sport. Brussels: Education and Culture Directorate General 2007.

20. Circumstances have changed considerably since these findings were published and the impact of the Greek economic crisis on government funding of such programmes is likely to be considerable.

21. Sector Skills Councils (SSCS) are independent, employer-led, UK-wide organisations that are licensed by government to build a skills system that employers want. SSCs goals include Improving learning supply through national occupational standards, Apprenticeships, and further and higher education.

22. Skills Active. Advanced apprenticeship in sporting excellence (AASE). In. London: Skills Active; 2010.

23. Nier $\mathrm{O}$. The development of academies for young professional rugby players in France. In: The Education of Elite Young Sportspersons in Europe. Edited by Amara M, Aquilina D, Henry I, Consultants P. London; 2004.

24. European Commission. White Paper on Sport. 2007: p. 6

25. Athletes to Business - A2B. Guidelines Promoting Dual Career in the EU. In. Brussels: European Olympic Committee EU Office; 2011.

26. op. cit. European Commission; 2012

27. Aquilina D, Henry I. Elite athletes and university education in Europe: a review of policy and practice in higher education in the European Union Member States. International Journal of Sport Policy and Politics 2010,2: p. 41

28. Aquilina D. Degrees of Success: Negotiating Dual Career Paths in Elite Sport and University Education in Finland, France and the UK. Loughborough: Loughborough University; 2009.

29. Miller R. Researching Life Stories and Family Histories. London: Sage; 1999.

27. Price N, Morrison N, Arnold S. Life out of the Limelight: Understanding the Non-sporting Pursuits of Elite Athletes. The International Journal of Sport and Society 2010,1:69-79.

\section{References}

Adecco. (2008). International Olympic Committee Athlete Career Programme in cooperation with Adecco Group. Retrieved 12 November 2012, 2012, from http://athlete.adecco.com/Pages/Home.aspx

Amara, M., Aquilina, D., Henry, I., \& PMP Consultants. (2004). Education of Elite Young Sportspersons in Europe. Brussels: European Commission: DG Education and Culture.

Aquilina, D. (2009). Degrees of Success: Negotiating Dual Career Paths in Elite Sport and University Education in Finland, France and the UK. Loughborough University, Loughborough.

Aquilina, D., \& Henry, I. (2010). Elite athletes and university education in Europe: a review of policy and practice in higher education in the European Union Member States. International Journal of Sport Policy and Politics, 2(1), 25-47. 
Athletes to Business - A2B. (2011). Guidelines Promoting Dual Career in the EU. Brussels: European Olympic Committee EU Office.

Brewer, B., Van Raalte, J., \& Petitpas, A. (2000). Self-Identity Issues in Sport Career Transitions. In D. Lavallee, Wylleman, P., (Ed.), Career Transitions in Sport: International Perspectives (pp. 2943): Fitness Information Technology.

Dacyshyn, A. (1999). When the balance is gone: the sport and retirement experiences of elite female gymnasts. In J. Coakley, Donnelly, P., (Ed.), Inside Sports (pp. 214-222): Routledge.

De Knop, P., Wylleman, P., Van Hoecke, J., De Martalaer, K., \& Bollaert, L. (1999). A European Approach to the management of the combination of academics and elite-level sport. Perspectives: The Interdisciplinary series of Physical Education and Sport Science: School Sports and Competition, 1, 49-62.

European Commission. (2007). White Paper on Sport. Brussles: Education and Culture Directorate General

European Commission. (2010). The Lisbon Treaty and EU Sports Policy. Brussels: Directorate General for Internal Policies: Policy Department B: Structural and Cohesion Policies.

European Commission. (2012). EU Guidelines on Dual Careers of Athletes: Recommended Policy Actions in Support of Dual Careers in High-Performance Sport (Approved by the EU Expert Group "Education \& Training in Sport" at its meeting in Poznań on 28 September 2012, forwarded for approval by the Council of Ministers and published, ENGSO web site). Brussels: Sport Unit, European Commission.

European Parliament. (2003). Combining Sport and Education: Support for athletes in the EU Member States. Luxembourg: European Parliament.

INEUM Consulting, \& TAJ. (2007). Study on the training of young sportsmen and sportswomen in Europe. Brussels: European Commission.

Lavallee, D. (2005). The Effect of a life development intervention on Sports career transition adjustment. The Sport Psychologist(19), 193-202.

Lavallee, D., Robinson, H.,. (2007). In pursuit of an identity: A qualitative exploration of retirement from women's artistic gymnastics. Psychology of Sport and Exercise(8), 119-141.

Miller, R. (1999). Researching Life Stories and Family Histories. London: Sage.

Nier, O. (2004). The development of academies for young professional rugby players in France. Paper presented at the The Education of Elite Young Sportspesons in Europe, London.

North, J., \& Lavallee, D. (2004). An investigation of potential users of career transition services in the United Kingdom. Psychology of Sport and Exercise(5), 77-84.

Price, N., Morrison, N., \& Arnold, S. (2010). Life out of the Limelight: Understanding the Non-sporting Pursuits of Elite Athletes. The International Journal of Sport and Society, 1(3), 69-79.

Skills Active. (2010). Advanced apprenticeship in sporting excellence (AASE). Retrieved 30 January 2011, from http://www.skillsactive.com/training/apprenticeships/aase

Stambulova, N. (2000). Athlete's Crises: A Developmental Perspective. International Journal of Sport Psychology(31), 584-601.

Stambulova, N., Stephan, Y., \& Japhag, U. (2007). Athletic retirement: A cross-national comparison of elite French and Swedish athletes. Psychology of Sport and Exercise(8), 101-118.

UK Sport. (2012). Performance Lifestyle. Retrieved 20 November 2012, 2012, from http://www.uksport.gov.uk/pages/performance-lifestyle/

Wylleman, P., Alfermann, D., \& Lavallee, D. (2004). Career transitions in sport: European Perspectives. Psychology of Sport and Exercise(5), 7-20.

Wylleman, P., \& Lavallee, D. (2004). A developmental Perspective on transitions faced by athletes. In M. Weiss (Ed.), Developmental Sport and Exercise Psychology: A lifespan perspective (pp. 503-523): Fitness Information Technology. 
Yannick, S., Bilard, J., Ninot, G., \& Delignieres, D. (2003). Repurcussions of Transition out of elite sport on subjective well-being: A one-year study. Journal of Applied Sport Psychology(15), 354-371. 